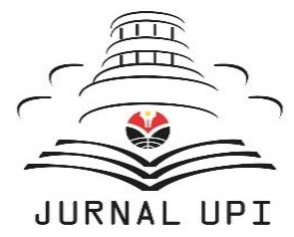

\title{
Exploring logical connectors in journals with different indexing levels: A comparison between international and national indexed journals
}

\author{
Eri Kurniawan*, Ruswan Dallyono, and Avika Cahyowati \\ Department of English Education, Faculty of Language and Literature Education, Universitas Pendidikan Indonesia, \\ Jalan Dr. Setiabudhi No. 229, Bandung, West Java, Indonesia
}

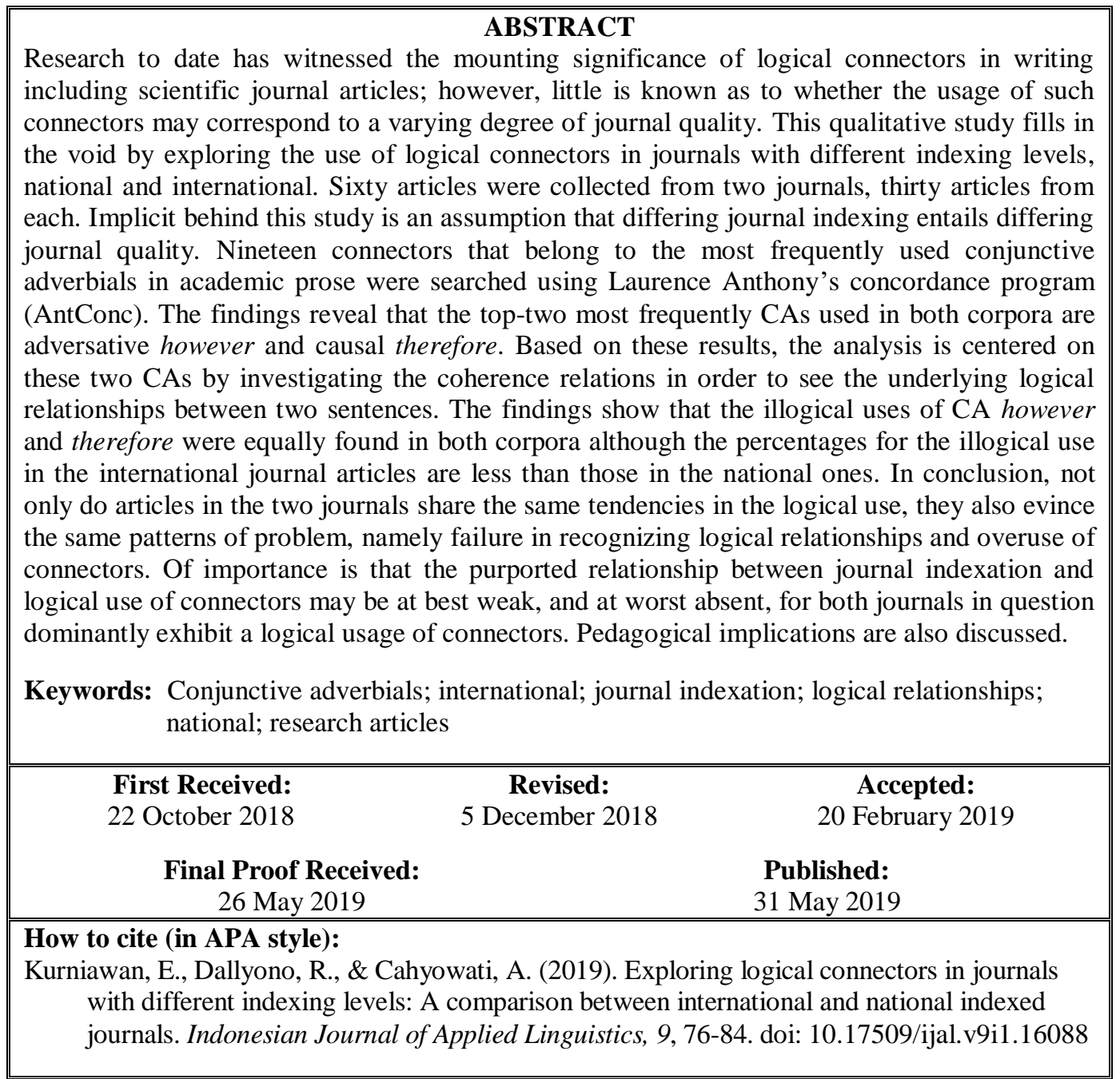

\section{INTRODUCTION}

Indexation of journals is considered a window to highquality research and publication. It is mostly known to be an efficient and objective database for literature researchers (Chadegani at al., 2013). Journal indexation is a common indicator that a journal is standard (Nagoba, Selkar, Mumbre, Davane, \& Suryawanshi, 2016). The essentials of being indexed are, more or less, similar to a domino effect: since the indexed journals will be accessible to a wide audience, they will have a fat chance to have a high reputation as the increase of readership (Rajagopalan, 2015). Indexed journals, then, are regarded as the world of research with higher scientific quality than non-indexed journals, besides being authoritative sources of scientific information (Balhara, 2012; Rajagopalan, 2015). Thus, with such benefits, no wonder academicians aspire to have their research articles published in indexed journals.

\footnotetext{
* Corresponding Author

Email: eri_kurniawan@upi.edu
} 
With the income of readership, internationally indexed journals certainly gain more visibility than local ones. Not merely on the scope of readers, international indexation also influences researchers' opportunities to collaborate with international researchers and of the article having additional citations, and therefore, that contributes to the community of the specific fields (Holland, Duncombe, \& Meester, 2018). With these profitable advantages come strict requirements for the publication: a research study should be the most up-todate and have the highest quality of interdisciplinary content. To ensure only the best quality of content in their publication, international research databases, for example, Scopus has a panel of independent, international board of journal editors, librarians, and bibliometricians (Rew, 2014). With such strict requirements and selection from the board, internationally indexed journals may have greater credibility than locally indexed counterparts; thus raising a stereotype that internationally indexed journals are higher in status than local ones.

As part of academic writing, research articles also hold the same rules of academic writing style, which emphasizes formal tone and, most importantly, a logical flow of ideas to form a unity (Labaree, 2009). A unified whole of ideas will help readers to follow the logical arguments in research articles and make sense of the content that is being communicated. However, the use of connectors as a device to intimately link ideas has evidently been troublesome for second language learners, especially for advanced learners (Yeung, 2009). It is, therefore, of interest to gauge the extent of use of logical connectors in academic writing.

There are various studies concerning how ideas are connected logically in research articles, and generally, in academic writing. By considering a great use of subordinate clauses in academic writing (Biber \& Gray, 2010), these studies mostly observe the use of logical connectors (conjunction-red) as a grammatical aspect in constructing the logical connection of ideas. Currently, research on logical connectors can be categorized into two major themes. First, there are those who investigated the use of logical connectors in relation to the linguistic background of the authors. These studies focus on the issue of L1 and L2 writing, investigating how Non-Native English Speakers (NNESs) build connection using connector tools (see Carió-Pastor; 2013; Chen, 2006; Esfandiari \& Barbary, 2017; Granger \& Tyson, 1996; Mur-Dueñas, 2009, 2011; Rojanavarakul \& Jaroongkhongdach, 2017; Uçar \& Yükselir, 2017; Yeung, 2009). Their methods are varied; some of them compared NNESs to Native English Speakers (NESs) while others only looked into NNESs' writing with different L1s. The results of their observations mostly point to evaluating pedagogical approaches in teaching academic writing to NNESs.

Meanwhile, other researchers tend to focus on logical connector use in relation to varied issues (see Gholami, Ilghami, Hossein, \& Tahoori, 2012; Karahan, 2015; Mahmoud, 2013; Martínez, 2015; Mohammed,
2015; Rahimi \& Qannadzadeh, 2010). The perspectives of the studies are multifarious, such as from the quality of texts, the area of disciplines, and even authors' intelligence. The results of these studies raise a new point of view in seeing that the use of connectors may not always be seen explicitly from the linguistic background of the authors, but it may also correlate with other backgrounds.

From the comparison of two categories of perspectives in analyzing logical connectors in writing, it may be seen that researchers tend to see connectors from the perspective of authors' linguistic background. A significant number of studies concerning the linguistic background of the authors may be traced to the aims of the research themselves; they are mostly seeking for efficient methods to teach connectors, especially to NNESs, to enhance the EFL/ESL students' understanding regarding how to properly use connectors. On the other hand, analysis of connector use involving other perspectives remains scant. Apart from the interests in observing NNESs writing, this lack may be due to the connector tools that are seen as a grammatical aspect in writing, which instinctively correlates with linguistics.

Seeing these two categories of logical connector studies, the lack of research concerning other views in analyzing the logical connector use in writing is the starting point of this current study. This study, then, falls into the second category, namely the hybrid category. One of the views that has been observed is the relation between text quality and the use of connectors (see Mohammed, 2015). In this paper, the current study goes beyond the quality of texts to question how the writing quality of research articles may be related to the use of logical connectors. To address such a question, this study investigates how logical connectors are used in two journals with different indexation: one indexed internationally and another indexed nationally. The study uses a qualitative analysis to seek for the possible differences occurring in both journals taken as the sample data. By conducting the study, the question of whether the difference in indexation level is potentially reflected in how the article is written in terms of logical cohesion may be fractionally answered.

\section{Logical connectors}

Logical connectors, as introduced by Celce-Murcia and Larsen-Freeman (1999) also known as conjunctives, refer to "what are traditionally called subordinating conjunctions and conjunctive adverbials" (p. 519). Subordinating conjunctions or what a typical grammar or writing book refer to as "adverbial subordinators", embeds one clause with the other with the force of adverbials. This type of connector is divided into two parts: simple and complex. On the other hand, conjunctive adverbials have a different main function to adverbials subordinators. The latter functions as the subordinators of two clauses; it connects two independent clauses. Although Celce-Murcia and Larsen-Freeman have different terms for the notion 
"conjunctions", they still admit the four broad classifications of conjunctions or logical connectors by Halliday and Hasan (2014) as follows.

1. Additive

emphatic: in addition, moreover, furthermore, besides, also appositional: that is, in other words, for instance comparative: likewise, similarly

2. Adversative

proper adversative: however, nevertheless, despite this, in contrast

contrastive: in fact, actually, however, on the other hand, at the same time

correction: instead, rather, on the contrary, at least

dismissal: in any case, anyhow, at any rate

3. Causal

general causal: therefore,

consequently, for that reason, thus

causal conditional:

then, in that case,

otherwise

4. Sequential

then, next, first, second, last, finally, up to now, to sum up

(Celce-Murcia \& Larsen-Freeman, 1999, p. 530)

Because Celce-Murcia and Larsen-Freeman adapt the broad classification by Halliday and Hasan (2014), the division of conjunctive adverbials above function the same. The term "additive" refers to those connectors that help add new information; "adversative" is used for presenting two contrasting ideas; "causal" defines causes and inferences; and "sequential" presents a realtime or sequential relationship.

This broad classification into four classes can solve a global problem, that is, to sort out the relations into types. This means that the categorization only works on a surface level, for example, the adversative class members are only used to counter the previous information. Further, Celce-Murcia and Larsen-Freeman (1999) argue that this categorization may result in a problem in relation to individual meaning. For example, despite belonging to the same class, writers cannot use nevertheless and despite this to the cases that should use however.

Highlighting this problem in their book, CelceMurcia and Larsen-Freeman (1999) present some propositional frames in order to guide writers, especially ESL/EFL, to use conjunctive adverbials properly. The propositional frames for the adversative class as a signal for countering information can be summarized in Table 1.

Some adverbials that belong to the additive class as a signal for involving new information are roughly described in Table 2.

The conjunctive adverbials that belong to the causal class are used to invite readers/listeners to make an inference of the situations. The propositional frames for this class are shown in Table 3.

Table 1. Propositional frames for adversative class (ibid., pp. 531-533)

\begin{tabular}{|c|c|c|}
\hline No. & $\mathbf{C A}$ & Use \\
\hline 1. & in any case & X implies Y, or not X implies Y \\
\hline \multirow[t]{2}{*}{2.} & Nevertheless & $\mathrm{X}$ implies $\mathrm{Y}$, and $\mathrm{X}$ is true, but \\
\hline & & $\begin{array}{l}\mathrm{Y} \text { is not true (nevertheless requires a situation in which one is led to expect one thing } \\
\text { but finds something different to be true) }\end{array}$ \\
\hline 3. & in contrast & $\begin{array}{l}X(a) \text { in contrast } Y(b) \text { (Two different topics or subjects are different in at least one } \\
\text { respect) }\end{array}$ \\
\hline 4. & on the other hand & $\begin{array}{l}\mathrm{X} \text { (a) on the other hand } \mathrm{X} \text { (b) (It is only necessary to have a single subject or topic, } \\
\text { which is then contrasted with respect to two contrasting qualities) }\end{array}$ \\
\hline \multirow[t]{3}{*}{5.} & however & Certainty versus uncertainty \\
\hline & & Semantic opposition \\
\hline & & Topic change marker \\
\hline
\end{tabular}

Table 2. Propositional frames for additive class (ibid., pp. 531-533)

\begin{tabular}{|c|c|c|}
\hline No. & CA & Use \\
\hline 1. & also & $\begin{array}{l}\text { Also is practically interchangeable with and, with a preference for identical subjects in } \\
\text { the two clauses. }\end{array}$ \\
\hline 2. & in addition & $\begin{array}{l}\text { In addition is practically interchangeable with } a n d \text {, with a preference for nonidentical } \\
\text { subjects. }\end{array}$ \\
\hline 3. & moreover & $\begin{array}{l}\text { Moreover is used primarily in arguments where several premises are used to support } \\
\text { conclusion of some sort. }\end{array}$ \\
\hline 4. & furthermore & $\begin{array}{l}\text { Furthermore is used like moreover, except that it tends to preface third or fourth } \\
\text { premises where more than two premises exist. }\end{array}$ \\
\hline \multirow[t]{2}{*}{5.} & similarly, likewise & $\begin{array}{l}\text { Similarly and likewise are used when there is some semantic similarity across two } \\
\text { predicates and when the two clauses in some way support a conclusion as supporting } \\
\text { examples. }\end{array}$ \\
\hline & & $\begin{array}{l}\text { Similarly seems to occur across clauses with two separate subjects, while likewise tends } \\
\text { to prefer just one. }\end{array}$ \\
\hline
\end{tabular}


Table 3. Propositional frames for causal class (ibid., pp. 531-533)

\begin{tabular}{|c|c|c|c|}
\hline No. & CA & Use & Example \\
\hline 1. & consequently & $\begin{array}{l}\text { Consequently is used to signal a real causal relationship } \\
\text { between two events or conditions. }\end{array}$ & $\begin{array}{l}\text { Greta won the lottery; consequently, } \\
\text { she bought a Ferrari. }\end{array}$ \\
\hline \multirow[t]{2}{*}{2.} & therefore & $\begin{array}{l}\text { Therefore, when used with causes, tends to be used when } \\
\text { listeners/readers are in a much better position to come to } \\
\text { the conclusion of their own. }\end{array}$ & $\begin{array}{l}\text { She won the lottery; therefore, she was } \\
\text { happy. }\end{array}$ \\
\hline & & $\begin{array}{l}\text { Therefore is also used in such a way as to invite } \\
\text { listeners/readers to construct an inference of a non-causal } \\
\text { type. }\end{array}$ & $\begin{array}{l}\text { The gun was under the bed; Smith had } \\
\text { a guilty look on his face; therefore, it } \\
\text { is likely that Smith committed the } \\
\text { crime. }\end{array}$ \\
\hline 3. & Thus & $\begin{array}{l}\text { Thus is used much like therefore, but therefore tends to be } \\
\text { used more often where there is a chain of premises in an } \\
\text { explicit argument. Thus may be used for parenthetical } \\
\text { "asides", where no explicit argument is intended. It seems } \\
\text { to be used in the same way as so, except that the register is } \\
\text { more formal and the word is found mostly in written prose. }\end{array}$ & \\
\hline
\end{tabular}

These propositional frames can help to make a thin border among each conjunctive adverbial that cannot be seen mainly from the categorization of class the conjunctive adverbial belongs. In addition, bordering the function of each conjunctive adverbial may reduce the probability of problems arising from the misuse, such as inappropriate register, failing on showing cohesive ties, and overuse.

\section{Previous studies}

The existing body of research on the usage of logical connectors can be categorized into two major themes. The first theme investigated the use of logical connectors in relation to the linguistic background of the authors, focusing on the use of connectors in L1 and/or L2 writing (inter alia Carió-Pastor; 2013; Chen, 2006; Esfandiari \& Barbary, 2017; Granger \& Tyson, 1996; Mur-Dueñas, 2009, 2011; Rojanavarakul \& Jaroongkhongdach, 2017; Uçar \& Yükselir, 2017; Yeung, 2012). With varying methods used and different groups of authors examined, the findings primarily point to the necessity to evaluate pedagogical approaches in teaching academic writing.

In some detail, Carió-Pastor (2013) observed the variation of connectors across different sections with different rhetorical moves in engineering RAs. The finding shows that the variation may exist as the interpersonal style is correspondence to the writers' linguistic background. In another study, Chen (2006) conducted a quantitative and qualitative study of the use of conjunctive adverbials (CAs) in advanced Taiwanese EFL learners' papers and prestige international articles. The quantitative study reveals that Taiwanese students overused connectors in word-level. Meanwhile, the qualitative analysis shows that they used certain CAs, such as besides and therefore, inappropriately.

Esfandiari and Barbary (2017) examined lexical bundles in psychology RAs from two corpora: English corpus (EC) and Persian corpus (PC), with a total of 4,370,630 words. This research was not directly related to analyzing logical connectors in RAs, however, it was found that the 4-word lexical bundles also function as transition signals. In a similar line, Granger and Tyson's (1996) observed how connectors are used in NS (Native
Speaker) and NNS (Non-Native Speaker) essays. The finding is the case of overuse and underuse of connectors are mostly in NNS essays.

Mur-Dueñas (2009) observed logical markers in business research articles from three corpora, RAs in English (L1 and L2) and Spanish (L1). The result shows that there is no significant difference between the use of additive, contrastive, and consecutive markers in English and Spanish RAs. Thus, there is no transfer process from L1 (Spanish) to L2 (English). In 2011, Mur-Dueñas conducted a similar study focusing on metadiscourse features with twenty-four business management RAs in English and Spanish. She found that the English RAs have a higher number of logical markers in comparison to Spanish RAs.

Quite recently, Rojanavarakul and Jaroongkhongdach (2017) investigated randomly selected twenty Thai research articles and twenty international research articles in the field of applied linguistics to discover the validity of the claim that Thai researchers have a lack of logical thinking (p. 328). The overall finding showed that "because", "thus" and "therefore" were the top three logical connectors used in both corpora. In addition, there was no difference in the number of logical and illogical cases between the two corpora. Therefore, proving that the claim may be invalid (p. 335).

Uçar and Yükselir (2017) narrowed their research to solely look at the logical connector "thus" in native speakers' and learners' corpora in the theoretical and applied linguistics field. The results indicate that "the Turkish English learners showed underuse in the use of connector "thus"" (p. 70), but they were advanced in discourse patterns of usage that they did not misuse the connector "thus". In a similar vein, Yeung (2009) investigated the use of "besides" in several NS openaccessed corpora and Hong Kong learners' corpus. The results from RAs across disciplines and abstracts corpora show no usage of connector "besides". This finding contrasts the learners' corpus that presents high usage of "besides". Thus, formal writing tends to avoid the use of "besides" as a connector.

Meanwhile, other researchers tend to focus on logical connector use in relation to varied issues (see 
Gholami et al., 2012; Karahan, 2015; Mahmoud, 2013; Martínez, 2015; Mohammed, 2015; Rahimi \& Qannadzadeh, 2010). The perspectives of the studies are multifarious, such as from the quality of texts, the area of disciplines, and even authors' intelligence. The results of these studies raise a new point of view in seeing that the use of connectors may not always be seen specifically from the linguistic background of the authors, but it may also correlate with other backgrounds.

Gholami et al. (2012) investigated the use of conjunctions in two disciplines: biomedicine and applied linguistics. The finding is "biomedical articles had more instances of conjunctions as cohesive devices than did applied linguistics articles" (p. 307). This result led up to a new assumption that biomedical articles might be more cohesive than applied linguistics articles.

Mahmoud (2013) observed sixty English essays written by Arabic speaking second-year English major students using a performance analysis approach. He discovered that the errors did not determine how good or weak a student is in English; the good and weak students "used most of the connectors correctly" (p. 185).

Martínez (2015) conducted a study to observe the relationship between conjunction density and grade level. It was found that the fourth-grade students outperformed third-grade students in terms of using conjunctions. However, from the perspective of qualitative analysis, there was a small amount of variation in conjunctions used, especially for third-grade students. In another study, Mohammed (2015) compared the use of connectors in high-rated and lowrated English learners' texts in twenty essays about The Whispering Trees plot summary. From the study, it was found that conjunctive "and" is less used in high-rated texts, but no significant difference for other conjunctives.

Rahimi and Qannadzadeh (2010) probed a possible relationship between the use of logical connectors and logical/mathematical intelligence in Iranian EFL essays. The result shows that the students with higher logical/mathematical intelligence tend to use more logical connectors.

All these previous studies have explored some variations in data-data across disciplines, researchers' nature, and length - and various findings have surfaced. This study, then, aims to open a new variation to the data, that is, use of connectors in journal research articles indexed in Scopus and non-Scopus, to discover whether the quality of research necessarily reflects in the logical use of connectors in writing. Note that any scientific journal research articles may have undergone an editing process; however, it is not yet clear whether the editing process is concerned with the use of logical connectors or predominantly focuses on the surface of linguistic corrections and writing formats.

\section{METHODS \\ Introducing the corpora}

The data were in the form of research articles collected from two journals with different indexation levels: one journal indexed in international indexation and one journal indexed in national indexation. Although they are different in terms of indexation levels, both journals are open-accessed, meaning that the archives are accessible for everyone. This made the process of data collection easier because the data are already computerized in the form of PDF (Portable Document Format). The similarity of both journals is also in terms of the area they cover, where both welcome papers on the area of linguistics, literature, and language education. Sixty English research articles were taken from both journals, thirty from each. This is considered a sufficient number because multiple sources are preferred to review, make sense, and organize into categories or theme.

\section{Introducing the data}

The sixty selected articles from two corpora were imported into Laurence Anthony's concordance program (AntConc), which is able to investigate almost any language patterns (Krieger, 2003). AntConc is also endowed with the feature of spotting a list of words in one search, rendering a search of CAs fast and easy. The academic prose list of CAs is adopted from Biber, Conrad, and Leech (2002), including nineteen CAs.

After removing concordance lines, the hits of the top-two CAs used in both corpora emerged. It can be noticed that the CA however surfaced with 305 hits, and the second-place CA therefore with 216 hits. Table 4 presents the top two CAs: however and therefore.

Table 4. The distribution of the top-two CAs

\begin{tabular}{llrc}
\hline \multirow{2}{*}{ Rank } & $\begin{array}{c}\text { Conjunctive } \\
\text { Adverbial }\end{array}$ & $\begin{array}{c}\text { Concordance Hits (based on } \\
\text { corpus) }\end{array}$ \\
\cline { 3 - 4 } & & INT & NAT \\
\hline 1 & However & 179 & 119 \\
2 & Therefore & 123 & 79 \\
\hline
\end{tabular}

\begin{abstract}
Analysis
Since the top-two most frequently used CAs in both groups of data are however and therefore, the analysis was based on the exception and result relations. Conjunctive adverbial however is included in the resemblance relation group that shows the relation of exception between two sentences or clauses. The constraint and expression of exception relation are shown in Figure 1.
\end{abstract}

Constraint: $p\left(p_{1}\right)$ and $\neg p\left(p_{2}\right) ; q_{\mathrm{i}}\left(a_{\mathrm{i}}\right) \subset q_{\mathrm{i}}\left(b_{\mathrm{i}}\right)$

Expression: Infer $p\left(a_{1}, a_{2}, \ldots\right)$ from the assertion of $S_{1}$ and $\neg p\left(b_{1}, b_{2}, \ldots\right)$ from the assertion of $S_{2}$, where $b_{\mathrm{i}}$ is a member or subset of $a_{\mathrm{i}}$ for some $i$.

Figure 1. Constraint and expression in exception relation (Kehler, 2002) 
From this constraint and expression, it can be seen that in using conjunctive adverbial however, one important thing to notice is that the entities $b_{1}, \ldots, b_{n}$ in the counter $p(\neg p)$ is a member of the entities $a_{1}, \ldots, a_{\mathrm{n}}$ in the preceding clauses.

In discussing the logical use of conjunctive adverbial however, it should be noted that this conjunctive adverbial functions not only as as a tool for exception information, but also for other purposes. According to
Celce-Murcia and Larsen Freeman (2016), there are three types of meanings signaled by however as exhibited in Table 5.

Meanwhile, conjunctive adverbial therefore belongs to the cause-effect relations to show the relation of result in two sentences. The constraint and expression in using the adverbial therefore are presented in Figure 2.

Table 5. Meanings signaled by however

\begin{tabular}{ll}
\hline \multicolumn{1}{c}{ Meaning } & \multicolumn{1}{c}{ Example } \\
\hline Certainty versus uncertainty & $\begin{array}{l}\text { We may go to Hawaii, or we may go to California. However, we have to find a way to escape the } \\
\text { snow this winter. }\end{array}$ \\
Semantic opposition & Jill doesn't do well in school. However, her sister is a straight A student. \\
Topic change marker & I lost $\$ 2,000$ in Las Vegas last week. However, let's talk about something else. \\
\hline
\end{tabular}

Constraint: $P \rightarrow Q$

Expression: Infer $P$ from the assertion of $S_{1}$ and

$Q$ from the assertion of $S_{2}$, where normally $P \rightarrow Q$.

Figure 2. Constraint and expression in result relation (Kehler, 2002)

\section{RESULTS}

\section{Logically used}

Most of the conjunctive adverbial however and therefore in both corpora are used logically, meaning that the underlying logical relationships connected by either conjunctive adverbial however or therefore fulfill the requirements. The logical use of conjunctive adverbial however and therefore is summarized in Table 6 and 7.

Table 6. Logically-used however

\begin{tabular}{lrr}
\hline \multicolumn{1}{c}{ Meanings } & INT (\%) & NAT (\%) \\
\cline { 3 - 4 } Exception & 1.6 & 1.1 \\
Semantic Opposition & 98.4 & 98.9 \\
Certainty vs. Uncertainty & 0 & 0 \\
Topic Change Marker & 0 & 0 \\
\hline
\end{tabular}

Table 7. Logically-used therefore

\begin{tabular}{ccc}
\hline Meaning & INT (\%) & NAT (\%) \\
\hline Result & 100 & 100 \\
\hline
\end{tabular}

From the tables above, it can be seen that the logical use of conjunctive adverbial however mostly centers on showing the semantic opposition relation rather than the other functions. Meanwhile, the logical use of conjunctive adverbial therefore stresses only on inferring the cause-effect relation.

\section{Illogically used}

The illogical use of conjunctive adverbial however and therefore in both corpora lies on the same problems: the error in recognizing the logical relationships underlying the sentences and overusing conjunctive adverbials. Under the unrecognizable logical relationships, there is a branching problem named the interchangeability of connectors in the same group; meanwhile, under the overuse problem, there is an underlying problem termed as surface logicality (see Discussion). These problems appeared in both corpora are shown in Table 8 and Table 9 as follows.

Table 8. Illogically-used however

\begin{tabular}{lcc}
\hline Problems & INT (\%) & NAT (\%) \\
\hline Error in recognizing logical relationships & 53.3 & 65.5 \\
- Interchangeable connectors & 12.5 & 0.00 \\
Overuse & 46.7 & 34.5 \\
\hline \multicolumn{3}{c}{ Table 9. Illogically-used } \\
\multicolumn{3}{c}{ therefore } \\
\hline Problems & INT $(\%)$ & NAT (\%) \\
\hline Error in recognizing logical relationships & 63.3 & 68 \\
- Surface logicality & 27.3 of 63.3 & 25 of 68 \\
Overuse & 36.7 & 32 \\
\hline
\end{tabular}

From the tables above, it can be noticed that the problem in using both conjunctive adverbials is mostly the failing in observing the underlying logical relationships between the sentences. Another point of interest in Table 8 is the fact that of the errors in recognizing logical relationships, interchangeable connectors are quite frequent. In Table 9, under the same category of the error as in Table 8, surface logicality occurs fairly dominantly. 


\section{DISCUSSION}

On account of the connectors being analyzed, the two journals under investigation instantiated the same trend of illogical uses of conjunctive adverbial however and therefore. This can be accounted for by referring to what Celce-Murcia and Larsen-Freeman (2016, 1999) have asserted concerning these two CAs: (i) studies concerning the use of connectors have identified adversative linking adverbs as one of the most difficult semantic categories; and (ii) conjunctive adverbial therefore is a frequently misused connector in students ${ }^{\text {ee }}$ writing. From the findings, it can be noticed that the percentages between the illogical uses of however and therefore show relatively insignificant differences. A number of plausible reasons behind this finding are deliberated as follows.

\section{Failure in recognizing logical relationships}

The study confirms a claim by Celce-Murcia and Larsen-Freeman (2016) that the failing in understanding of the logical relationships between sentences or longer texts may contribute to the error production. The meanings of some linking adverbs may be easy to identify, but the failure comes in identifying the logical relationships. This is also based on studies on ESL/EFL students, and this paper demonstrates the same type of case. Some misuses found in the current study are confusions of logical relationships that result in the illogical relation between the sentences connected by either however or therefore. The misunderstanding of logical relationships is evident in the following example:

\section{[Exc. 20] Excerpt from INT-02 - Illogical Use}

On the fairness criterion, the scores obtained by the respondents are quite varied with a range of 2 to 4 , no one can reach the score

However, nine (30\%) respondents scored 2, 16 (53\%) respondents scored 3 , and five $(17 \%)$ respondents scored 4 respectively.

In [Exc. 20], the initial sentence talks about the overall result taken from the scores of the respondents; meanwhile, the second sentence specifies the overall result. Seeing what these two sentences bring, the use of conjunctive adverbial however to connect both ideas is incorrect. Thus, this proves that there is a misunderstanding in seeing the logical relationship underlying the sentences.

\section{'Misunderstanding' in using adversative CAs}

Although the main issue in illogical use occurrences is the error in logical relationship comprehension, the current study also attests Celce-Murcia and Larsen Freeman's (1999) statement that the errors in using connectors may also happen because of the "misunderstanding" that words and phrases under the same category are interchangeable, especially in adversative linking adverbs. This case is noticeable in the following example:
[Exc. 21] Excerpt from INT-11 - Illogical Use Many Indonesian speakers believe that almost all their national language vocabulary has been borrowed from foreign sources, and sometimes they seem to regret this situation, as if it were offending for their sense of national pride. However, this is not true.

What appears in [Exc. 21] is that the second sentence contrasts the preceding sentence by rejecting the statement. On account of this, the use of CA however to connect both sentences is incorrect; it should be connected by on the contrary. CA on the contrary works to cancel out the previous statement (Crewe, 1990).

\section{Surface-level fillers}

Besides confirming the reasons for error production in using adverbial however and therefore, the findings of the current study also corroborate what Crewe (1990) states as the "surface logicality", that is "to impose surface logicality on a piece of writing where no deep logicality exists" (ibid., p. 320). In other words, the use of a certain conjunctive adverbial in connecting two clauses may not have a meaning in deep logicality. The surface logicality proposed by Crewe (1990) occurs in a considerable number of cases in both INT and NAT data. An instance of surface logicality is as follows.

\section{[Exc. 22] Excerpt from INT-23 - Illogical Use}

On the other hand, the Philippines consists of 18 administrative regions; therefore, in order to conduct similar all-inclusive research study, convenience sample data of 139 subjects were taken from 5th semesters students in Philippine Women's University in the city of Manila and Southern Baptist College in North Cotabato.

In [Exc. 22], it shows the initial clause talking about the number of administrative regions in the Philippines; meanwhile, the second clause specifies the data collection. Both clauses are connected by conjunctive adverbial therefore, which cannot encode the relation between the two clauses. Thus, the relation built by the use of therefore is nonexistent.

\section{Logical leap}

The study is also in line with Chen's (2006) that correlates her study with Crewe (1990), especially regarding the theory about surface logicality. The present study also discovered the similar cases in both INT and NAT data. Such an error is exemplified in the followings:

\section{[Exc. 23] Excerpt from INT-23 - Illogical Use} According to Pennycook (2006), it is not that people use language varieties because of who they are, but rather people perform who they are by using different language varieties.

Therefore, the aim of this paper is to compare between Filipinos and Indians the preferred models of English for personal, national, and international communication. 
[Exc. 24] Excerpt from NAT-26 - Illogical Use Since creating a sound English curriculum is not an easy thing to do, a careful examination on English in the preschool curriculum needs to be performed. This study therefore aims to find out the goals of integrating English as an intra-school curriculum in a preschool in Bandung and the teacher's attempts to achieve these goals in terms of four basic components of curriculum taken from Cayadong (2011) and Tyler (Posner, 1992); the objectives, the materials, the methods and the assessments.

[Exc. 23] and [Exc. 24] are the illustrations of "logical leap". In [Exc. 23], this study leaps from the reason for performing language varieties to stating the aim of the paper. The argument in the first sentence (it is not that people use language varieties because of who they are, but rather people perform who they are by using different language varieties) is not the reason for the study to be conducted. The same case also happens in NAT data such as in [Exc. 24]. The condition shown in the initial sentence about a must to perform a careful examination is not the cause of the study.

Despite those illogical relations, the analysis of the uses of conjunctive adverbial however and therefore in INT and NAT data is in line with the semantic opposition function of however (Celce-Murcia \& Larsen-Freeman, 2016) and Kehler's (2002) resemblance and cause-effect relations, as evidenced by the percentages of conjunctive adverbial however functioning as semantic opposition that almost reach a hundred percent. Besides, Kehler's (2002) adaptation of Hobbs's (1990) theory concerning coherence relations is also confirmed in the study. As a signal of exception relation, conjunctive adverbial however appears in some logical relations, showing the deep relation between the entities in S1 and S2. Kehler's (2002) theory also frames the use of therefore in the analysis, confirming that the semantic notation of result relation $(P \rightarrow Q)$ works in the analysis, apart from the errors of logical relationships.

On the whole, from the analysis of top-two most frequently used conjunctive adverbials in two journals with different indexing levels, the findings reveal that while the articles in the two journals share the same tendencies in the logical use, they also evince the same patterns of problem, namely failure in recognizing logical relationships and overuse of connectors. This suggests that the purported relationship between journal indexation - in this respect, national and internationaland logical use of connectors may be at best weak, and at worst absent, for both journals in question dominantly exhibit a logical usage of connectors. This claim, of course, warrants further inquiries.

\section{CONCLUSIONS}

This study has examined the use of logical connectors in two journals with different indexation levels: a national index and a scopus-index. The findings demonstrate the articles of the two differently-indexed journals exhibit two main tendencies, i) the dominant usage of logical use of connectors, which results in the logical flow of ideas between the sentences; and ii) the same patterns of illogical use, namely failure in recognizing logical relationships and overuse of connectors. This is understandable to some extent because however is the most difficult connector to use and therefore is frequently misused (Celce-Murcia \& Larsen-Freeman, 1999; 2016). These findings bear implications for the assumed relationship between journal indexation and logical use of connectors. Given the aforementioned patterns, such a relationship is called into question. Further examinations with a larger amount of data are needed to validate this claim.

From the findings of this study, a number of future studies in investigating the use of conjunctive adverbials in academic prose, especially in research articles may be proposed. For example, an in-depth analysis can be conducted in regards to the use of conjunctive adverbials from other classes. A future study may probe a claim by Celce-Murcia and Larsen-Freeman (2016) that adversative class proves as the most difficult one to use because of the members' interchangeability traits. This may be conducted by comparing the use of adversatives in NES' (Native English Speakers) and NNES' (Non-Native English Speakers) research articles. Another future study may look at the case of informal conjunctive adverbials that 'make way' into formal register, such as academic prose. Some studies, such as Field and Yip (1992), Chen (2006), and Yeung (2012), may become the base of the study. One may examine this case in relation to the linguistic background of the authors or across disciplines.

Pedagogically, it is adviseable that grammar and (academic) writing courses take into account explicit teaching techniques such data driven learning in order to raise student awareness of the logical usage of conjunctive advebials especially the connectors that share similarity and thus are often used interchangeably. This is so because, as alluded to by Uçar \& Yükselir (2017), "conventional ways of teaching and conventional theories seem to be inadequate for gaining necessary knowledge of connectors" (p. 71).

\section{REFERENCES}

Balhara, Y. (2012). Indexed journal: What does it mean? Lung India, 29(2), 193.

Biber, D., \& Gray B. (2010). Challenging stereotypes about academic writing: Complexity, elaboration, explicitness. Journal of English for Academic Purposes, 9(1), 2-20.

Biber, D., Conrad, S., \& Leech, G. (2002). Student grammar of spoken and written English. Essex: Longman.

Carió-Pastor, M. (2013). A contrastive study of the variation of sentence connectors in academic English. Journal of English for Academic Purposes, 12, 192-202. 
Celce-Murcia, M., \& Larsen-Freeman, D. (1999). The grammar book: An ESL/EFL teacher's course (2nd ed.). Boston: Heinle \& Heinle Publishers.

Celce-Murcia, M., \& Larsen-Freeman, D. (2016). The grammar book: Form, meaning, and use for English language teachers ( $3^{\text {rd }}$ ed.). Boston: National Geographic Learning.

Chadegani, A., Salehi, H., Yunus, M., Farhadi, H., Fooladi, M., Farhadi, M., \& Ale Ebrahim, N. (2013). A comparison between two main academic literature collections: Web of Science and Scopus databases. Asian Social Science, 9(5), 18-26.

Chen, C. (2006). The use of conjunctive adverbials in the academic papers of advanced Taiwanese EFL learners. International Journal of Corpus Linguistics, 11(1), 113-130.

Crewe, W. (1990). The illogic of logical connectives. ELT Journal, 44(4), 316-325.

Esfandiari, R., \& Barbary, F. (2017). A contrastive corpus-driven study of lexical bundles between English writers and Persian writers in psychology research articles. Journal of English for Academic Purposes, 29, 21-42.

Field, Y., \& Yip, L.M.O. (1992) A comparison of internal conjunctive cohesion in the English essay writing of Cantonese speakers and native speakers of English. RELC Journal, 23(1):15-28.

Gholami, J., Ilghami, R., Hossein, H., \& Tahoori, F. (2012). Cohesive devices in Iranian research papers across social sciences and medical sciences: The case of conjunctives in papers on biomedicine and applied linguistics. The Iranian EFL Journal, 8(4), 292-309.

Granger, S., \& Tyson, S. (1996). Connector usage in the English essay writing of native and non-native EFL speakers of English. World Englishes, 15(1), 17-27.

Halliday, M. A. K., \& Hasan, R. (2014). Cohesion in English. London: Routledge.

Hobbs, J. R. (1990). Literature and cognition. Stanford, CA: CSLI Publications.

Holland, K., D. Duncombe, E. D., \& W. Meester. (September, 2014). Scopus journal FAQs: Helping to improve the submission \& success process for editors \& publishers. Retrieved April 20, 2016, from

https://www.elsevier.com/__data/assets/pdf_file/0 006/95118/SC_FAQ-content-selectionprocess22092014.pdf

Karahan, P. (2015). A diagnostic analysis of ELT students' use of connectives. Procedia-Social and Behavioral Sciences, 199, 325-333.

Kehler, A. (2002). Coherence, reference, and the theory of grammar. Stanford, CA: CSLI Publications.

Krieger, D. (2003). Corpus linguistics: What it is and how it can be applied to teaching. The Internet TESL Journal, 9.

Labaree, R. V. (2009). Organizing your social sciences research paper: Academic writing style. Retrieved from https://libguides.usc.edu/writingguide

Mahmoud, A. (2013). The use of logical connectors by Arab EFL university students: A performance analysis. International Review of Social Sciences and Humanities, 7, 176-188.

Martínez, A. (2015). Use of conjunctions in the compositions of secondary education students. Procedia - Social and Behavioral Sciences, 212, 42- 46.

Mohammed, A. (2015). Conjunctions as cohesive devices in the writings of English as second language learners. Procedia - Social and Behavioral Sciences, 208, 74-81.

Mur-Dueñas, P. (2009). Logical markers in L1 (Spanish and English) and L2 (English) business research articles. English Text Construction, 2(2), 246-264.

Mur-Dueñas, P. (2011). An intercultural analysis of metadiscourse features in research articles written in English and in Spanish. Journal of Pragmatics, 43(12), 3068-3079.

Mur-Dueñas, P. (2011). An intercultural analysis of metadiscourse features in research articles written in English and in Spanish. Journal of Pragmatics, 43(12), 3068-3079.

Nagoba, B., Selkar, S., Mumbre, S., Davane, M., \& Suryawanshi, N. (2016). Where to publish? Choosing the right journal for research work. Journal of Krishna Institute of Medical Sciences University, 5(3), 136-141.

Rahimi, A., \& Qannadzadeh, J. (2010). Quantitative usage of logical connectors in Iranians' EFL Essay writing and logical and linguistic intelligences. Procedia - Social and Behavioral Sciences, 5 , 2012-2019.

Rajagopalan, J. (2015, May 20). Journal indexing 101: Understanding the basics. Retrieved from https://www.editage.com/insights/journalindexing-101-understanding-the-basics

Rojanavarakul, T., \& Jaroongkhongdach, W. (2017). Exploring logical thinking through the use of logical connectors in Thai and international research articles. Online Proceedings of the International Conference: DRAL 3/19th ESEA 2017, 328-337.

Uçar, S., \& Yükselir, C. (2017). A corpus-based study on the use of the logical connector 'thus' in the academic writing of Turkish EFL learners. English Language Teaching, 10(2), 64-72.

Yeung, L. (2012). Use and misuse of "besides": A corpus study comparing native speakers' and learners' English. System, 37, 330-342. 